Atos de Pesquisa em Educação - ISSN 1809-0354

Blumenau, v.14, n.1, p.219-241, jan./abr. 2019

DOI: http://dx.doi.org/10.7867/1809-0354.2019v14n1p219-241

\title{
CLUBE DE CIÊNCIAS: VIABILIZANDO A DEMOCRATIZAÇÃO CIENTÍFICA
}

SCIENCE CLUB: ENABLING THE SCIENTIFIC DEMOCRATIZATION

CLUB DE CIENCIAS: VIABILIZANDO LA DEMOCRATIZACIÓN CIENTÍFICA

SILVA, Patrícia do Socorro de Campos da
patt.help@gmail.com
Prefeitura da Cidade do Rio de Janeiro
SANTOS, Sonia Barbosa dos
gundlachia@yahoo.com.br
Universidade do Estado do Rio de Janeiro
RÔÇAS, Giselle Fonseca
giselle.rocas@ifrj.edu.br

Instituto Federal de Educação, Ciência e Tecnologia do Rio de Janeiro

RESUMO O Brasil já teve diversas fases e estratégias de divulgação científica. Nas últimas décadas, embora tenha crescido o número de centros de ciência, ainda há uma desigualdade na disponibilização dos conhecimentos científicos. Portanto, são necessárias ferramentas que democratizem a ciência entre grupos sociais desprivilegiados. Assim, este trabalho objetiva apresentar um relato de experiência de atividades desenvolvidas por um Clube de Ciências (de uma escola pública do Rio de Janeiro) que visaram a aproximar a ciência dos alunos e discutir a sua importância, bem como o envolvimento de cientistas, para a democratização da ciência e formação científica e cidadã desses alunos. Consideramos que o projeto tem sido um instrumento de redução desta desigualdade no acesso, na compreensão e na discussão sobre a ciência.

Palavras-chave: Clube de Ciências. Democratização científica. Divulgação da Ciência. Escola Pública.

ABSTRACT Brazil has gone several strategies of scientific dissemination. Although the number of science centers has grown up, there is an inequality in the availability of scientific knowledge. Therefore, tools that democratize science among disadvantaged social groups are required. The objective of this paper is to present an account of experience activities developed by the Science Club that facilitated a rapprochement between public school students and science, and discuss the importance of activities, as well as the involvement of scientists in this process, in the democratization of science and in the scientific and citizen education of these students. We consider that the Science Club has reduced inequality in access, understanding and discussion about science. 


\section{Atos de Pesquisa em Educação - ISSN 1809-0354 \\ Blumenau, v.14, n.1, p.219-241, jan./abr. 2019 \\ DOI: http://dx.doi.org/10.7867/1809-0354.2019v14n1p219-241}

Keywords: Non- formal educational space. Public school. Science Club. Scientific democratization.

RESUMEN Brasil ya ha tenido varias fases y estrategias de divulgación científica. En las últimas décadas, aunque ha crecido el número de centros de ciencia, todavía existe desigualdad en acceso a los conocimientos científicos. Por lo tanto, son necesarias herramientas que democratizen la ciencia entre grupos sociales desfavorecidos. Así, este trabajo tiene como objetivo presentar un relato de experiencia de actividades desarrolladas por un Club de Ciencias de una escuela pública de Río de Janeiro que pretendían acercar la ciencia de los alumnos y discutir su importancia, así como la implicación de científicos, democratización de la ciencia y formación científica y ciudadana de esos alumnos. Consideramos que el proyecto ha sido un instrumento de reducción de esta desigualdad en el acceso, la comprensión y la discusión sobre la ciencia.

Palabras clave: Club de Ciencias. Democratización científica. Escuela pública. Divulgación de la Ciencia.

\section{INTRODUÇÃO}

Muitos autores acreditam que a divulgação científica se iniciou entre os séculos XVI e XVII na Europa, quando os cientistas divulgavam suas descobertas e seus experimentos entre si, principalmente por meio de cartas e livros e também nas reuniões das academias de ciências (SCHWARZTMAN, 2001; MASSARANI; MOREIRA, 2004; CALVO HERNANDO, 2006; SILVA, 2006; TOMÁS, 2006). Posteriormente, a divulgação científica se deu também por meio de exposições públicas, em que os cientistas apresentavam experimentos aos leigos e palestravam sobre suas pesquisas; e, mais tarde, quando os cientistas passaram a produzir textos em línguas vernáculas, acessíveis a todos (CALVO HERNANDO, 2006; SILVA, 2006; TOMÁS, 2006).

No Brasil, as primeiras manifestações de divulgação científica se iniciaram no século XIX com a criação das primeiras instituições de ensino superior, ou instituições com algum interesse pela ciência, como: Real Horto, em 1808, (denominado mais tarde de Jardim Botânico); Academia Militar, em 1810; Museu Real, em 1818; Museu Imperial, Museu Nacional e o Imperial Observatório, em 1827; e a Imprensa Régia, em 1810, que deu início a publicação de revistas, livros, jornais, manuais de ciências e textos voltados para a educação científica (MASSARANI; MOREIRA, 2003; 2004; VALENTE; CAZELLI; ALVES, 2005). 


\section{Atos de Pesquisa em Educação - ISSN 1809-0354}

\section{Blumenau, v.14, n.1, p.219-241, jan./abr. 2019}

DOI: http://dx.doi.org/10.7867/1809-0354.2019v14n1p219-241

O interesse do imperador Dom Pedro II pela ciência auxiliou na difusão de conhecimento, resultando no aumento de atividades de divulgação científica e de periódicos ligados à ciência durante a segunda metade do século XIX. Surgiram, então, diversas revistas científicas; o primeiro livro brasileiro de ficção científica Doutor Benignus (1875) (MASSARANI; MOREIRA, 2003; 2004); as "Conferências Populares da Glória", iniciadas em 1873 - atividades de divulgação científica da cidade do Rio de Janeiro que tratavam de diversos temas com a população - e os "Cursos Públicos do Museu", por volta de 1876 - atividade de divulgação científica ministrada pelo Museu Imperial a pessoas comuns. Esses cursos e palestras também aconteciam no Museu Nacional (JACOBUCCI, 2008; VALENTE; CAZELLI; ALVES, 2005).

Já no século $X X$, com o fortalecimento das iniciativas para a divulgação científica, surgiu a Sociedade Brasileira de Ciências (1916), transformada em seguida (1922) em Academia Brasileira de Ciências, a partir da qual surgiu, em 1923, a Rádio Sociedade do Rio de Janeiro (hoje Rádio MEC), com o objetivo de divulgar a ciência, além de promover discussões educacionais e culturais (MASSARANI; MOREIRA, 2003; 2004). Logo surgiram diversas revistas, livros e coleções que visavam à divulgação científica. Os jornais abriram espaço para a ciência e passaram a favorecer as atividades científicas e as visitas de cientistas estrangeiros ao nosso país. A Associação Brasileira de Educação (década de 1920) desenvolvia cursos, conferências e palestras destinadas ao público leigo, inclusive com apresentação de diversos cientistas de destaque da época. Outros instrumentos de divulgação criados foram o Instituto Nacional do Cinema Educativo (INCE - 1930-1960), que produziu filmes visando à educação em ciências e/ou para a divulgação da ciência, e a Rádio Escola Municipal (1934), (denominada mais tarde de Rádio Roquette-Pinto) que desenvolvia programas de apoio ao ensino formal com objetivo de gerar curiosidade nas crianças, principalmente pela ciência (MASSARANI; MOREIRA, 2004).

Os meios de comunicação não específicos aumentaram as possibilidades para esse tipo de divulgação, como a rádio Jornal do Brasil (década de 1930), o jornal Folha de São Paulo (década de 1940) e o jornal A Manhã (por volta da década 
de 1950) - este último, inclusive, tinha um suplemento chamado 'Ciências para Todos' (ESTEVES; MASSARANI; MOREIRA, 2003).

No final da década de 1940, surge a Sociedade Brasileira para o Progresso da Ciência, com o objetivo de reunir cientistas brasileiros para ampliar a divulgação científica no Brasil e discutir problemas da ciência no país (MASSARANI; MOREIRA, 2003).

Em 1957, o lançamento do Sputinik marcou a sociedade como grande progresso científico. O acontecimento levou a uma grande mudança estrutural e curricular da educação norte americana, visando à prática experimental dos alunos com os projetos School Mathematics Study Group (SMSG) e o Biological Science Curriculum Study (BSCS) (KRASILCHIK, 1987) - assim como em outros países. No Brasil, também ocorreu o fortalecimento do ensino experimental visando à formação de minicientistas. Neste momento, inicia-se a criação de centros de ciências voltados para o fortalecimento do ensino formal - focando na reprodução do conhecimento prático da ciência - e para a preparação dos professores de ciências ${ }^{1}$ (VALENTE; CAZELLI; ALVES, 2005).

No fim dos anos de 1970, cientistas voltaram a considerar a divulgação científica como ponto chave para o desenvolvimento social do país, redirecionando os centros de ciências para o ensino não formal. Nesta retomada, surge, na década de 1980, o ciclo de palestras públicas chamado "Seis e meia da Ciência" e é criada a revista Ciência Hoje, ambas ligadas à Sociedade Brasileira para o Progresso da Ciência, que pretendiam dispor de espaço para cientistas brasileiros apresentarem suas pesquisas ao público. Surgem programas de educação científica, como o Subprograma Educação para a Ciência (SPEC) da CAPES (VALENTE; CAZELLI; ALVES, 2005). Em seguida, surgem outras publicações específicas (como, por exemplo, Superinteressante e Scientific American Brasil), e seções de ciência em jornais de grande circulação, além de programas de televisão que tratam da ciência

\footnotetext{
${ }^{1}$ Centro de Ensino de Ciências do Nordeste (CECINE), Centro de Ciências da Bahia (CECIBA), Centro de Ciências de Minas Gerais (CECIMIG), Centro de Ciências da Guanabara (CECIGUA), Centro de Ciências de (CECIRS). Segundo Valente et al.(2005) esses centros eram financiados pelo Ministério da Educação e Cultura e tiveram uma atuação marcante na formação continuada de professores através de cursos de treinamento, especialização, aperfeiçoamento e seminários. Também editavam e distribuíam publicações, elaboravam e traduziam projetos especiais e prestavam assistência e orientação pedagógicas permanentes.
} 


\section{Atos de Pesquisa em Educação - ISSN 1809-0354 \\ Blumenau, v.14, n.1, p.219-241, jan./abr. 2019 \\ DOI: http://dx.doi.org/10.7867/1809-0354.2019v14n1p219-241}

em algum nível (Globo Ciência, Globo Ecologia, Nossa Ciência da TV Educativa TVE, entre outros) (MASSARANI; MAGALHÃES; MOREIRA, 2003).

Neste contexto, foi fortalecida a criação de diversos museus e centros de ciências no país, que foram crescendo ao longo dos anos de 1980 e 1990, com objetivos e perspectivas distintas, mas sempre com foco na divulgação da ciência. Alguns exemplos de museus criados na década de 1980 são: no Rio de Janeiro, o Espaço Ciência Viva e o Museu de Astronomia e Ciências Afins (MAST); em São Paulo, o Centro de Divulgação Científica e Cultural (CDCC) da Universidade de São Paulo (USP/ São Carlos), a Estação Ciência e o Museu Dinâmico de Ciências de Campinas da Universidade de Campinas (Unicamp) e Prefeitura de Campinas; na Bahia, o Museu de Ciência e Tecnologia da Universidade do Estado da Bahia (UNEB) (VALENTE; CAZELLI; ALVES, 2005). Alguns exemplos de museus criados na década de 1990 são: no Rio Grande do Sul, o Museu de Ciência e Tecnologia (da Pontifícia Universidade Católica do Rio Grande do Sul - PUC-RS); em Pernambuco, o Espaço Ciência; no Rio de Janeiro, o Espaço Museu da Vida, (da Casa de Oswaldo Cruz/Fundação Oswaldo Cruz) e o Espaço Museu do Universo, da Fundação Planetário.

Embora, ao longo dos anos de 1990 e início dos anos 2000, tenham sido criados tantos centros de divulgação científica, segundo Massarani e Moreira (2004), o Mapa da Ciência, elaborado pela FAPERJ em 2002, mostrava um baixo índice de visitação desses espaços. Jacobucci (2008), citando Hamburguer (2001), apresenta dados e discute esta problemática dizendo que, embora o Brasil tivesse, em 1997, 670 museus e seja um país de grande população, verificava-se que os nossos museus eram pouco visitados, exibindo a mesma conclusão que Massarani e Moreira (2004). Esses dados podem indicar que a ciência ainda não faz parte de nossa cultura e que a divulgação da ciência ainda tem dificuldade em alcançar grande parte da população.

Assim como os últimos autores citados, Gil-Perez et al. (2001) e Valente; Cazelli; Alves (2005) abordaram a discriminação social relacionada à ciência. Ou seja, a dificuldade que alguns grupos sociais têm de acessar a ciência, seja devido ao simples desconhecimento, seja devido à dificuldade de acesso por questões financeiras ou geográficas; e acrescento: seja devido à linguagem. Almeida (2005) 


\section{Atos de Pesquisa em Educação - ISSN 1809-0354 \\ Blumenau, v.14, n.1, p.219-241, jan./abr. 2019 \\ DOI: http://dx.doi.org/10.7867/1809-0354.2019v14n1p219-241}

chama a nossa atenção para o fato de que os visitantes de museus (consumidores culturais) são, em sua enorme maioria, pessoas que possuem nível superior de escolaridade e renda alta. Albagli (1996) também destacou este desequilíbrio. A autora discutiu sobre a desigualdade existente na disponibilização desses conhecimentos entre países desenvolvidos e os em desenvolvimento: sendo grande e evidente nos primeiros e muito discreto nos segundos, ficando clara a desigualdade na disponibilização desses conhecimentos nos diferentes segmentos sociais.

Sobre essa problemática Massarani e Moreira afirmaram que:

[...] profundas desigualdades na distribuição das oportunidades educacionais e do conhecimento são ainda um desafio grande no país e na cidade do Rio de Janeiro. Isto se reflete também nas atividades de popularização da ciência que, em geral, estão concentradas nos grandes centros urbanos e, nestes, em regiões de classe média. A incorporação de grandes parcelas marginalizadas da população, em uma cidade partida, é uma tarefa importante, cuja chance de êxito dependerá do estabelecimento de um processo coletivo suficientemente amplo, que envolva instituições de pesquisa, universidades, órgãos governamentais, cientistas, comunicadores, pesquisadores, professores e estudantes (MASSARANI; MOREIRA, 2003, p.64 e 65).

Segundo Ivanissevich (2009), a popularização da ciência pode funcionar como instrumento de inclusão social da população e, como tal, "deve atingir todas as camadas e faixas etárias da sociedade" (IVANISSEVICH, 2009, p. 5). Essa democratização da ciência, destacada por diversos autores e comentada por Massarani e Moreira (2004), não deve passar apenas pelo conhecer a ciência, mas também pela disponibilização de mecanismos que facilitem o envolvimento, a discussão, a participação e o questionamento sobre a ciência e seus objetivos (DUARTE, 2004).

É nesse ponto que se insere o Clube de Ciências que desenvolvemos desde 2012 na Escola Municipal Telêmaco Gonçalves Maia (E.M.TGM). Esse projeto funciona como uma ferramenta que permite, facilita e incentiva a redução da desigualdade no acesso, na compreensão e na discussão sobre a ciência e sobre a produção científica.

A Escola Municipal Telêmaco Gonçalves Maia (escola de segundo segmento do Ensino fundamental) está localizada no bairro da Pavuna, na cidade do Rio de Janeiro, área com baixos índices de desenvolvimento humano (IPP, 2004) e altas taxas de violência (ISP, 2015). Os alunos desta realidade escolar se inserem no 
 \\ Blumenau, v.14, n.1, p.219-241, jan./abr. 2019 \\ DOI: http://dx.doi.org/10.7867/1809-0354.2019v14n1p219-241}

grupo marginalizado citado e, mesmo havendo tantos centros de ciências pelo estado e na cidade do Rio de Janeiro, ainda não tiveram a oportunidade de desfrutálos: muitos nem saem da região da Pavuna, onde moram, e a divulgação que conhecem é a da violência. Assim, acreditamos que propor um projeto sobre um Clube de Ciências tem papel fundamental na mudança dessa condição. Esse projeto, assim como qualquer categoria de processo educativo, enquanto modo de mobilização social e como uma intervenção, pode trabalhar para a mudança desta situação injusta. Este projeto, mesmo atingindo uma pequeníssima parcela daquela comunidade, vem se inserindo entre alguns "destituídos da ciência", facilitando e viabilizando o encontro entre o indivíduo e a ciência.

Sobre essa discussão, o cientista Marcelo Gleiser (BARATA, 2008), em entrevista, fala que:

[...] os problemas educacionais de nosso país são imensos; o analfabetismo, a situação precária do ensino público, a pobreza que tira as crianças das escolas. Vivemos uma situação paradoxal, onde o Brasil está entre os dez países mais ricos do mundo e vemos ainda pobreza por toda a parte. A divulgação científica não é acura desses males, mas pode ajudar. $\mathrm{Na}$ medida em que mostramos aos jovens de todas as classes sociais a importância da educação num mundo onde informação é o bem mais valorizado, quando mostramos que a ciência tem a capacidade de mudar a sociedade de forma profunda, quando educamos de modo a construir uma sociedade capaz de decidir seu próprio futuro e não de ser manipulada por políticos ou potências externas, fazemos nossa parte (BARATA, 2008, p.13 e 14).

Com esse mesmo objetivo, o Clube de Ciências da E.M.TGM desenvolveu atividades que facilitaram essa aproximação ao longo desses cinco anos.

\section{O CLUBE DE CIÊNCIAS}

O Clube de Ciências da Escola Municipal Telêmaco Gonçalves Maia foi criado em 2012. A iniciativa partiu da primeira autora, docente efetiva da escola, que buscou parceria junto à Universidade do Estado do Rio de Janeiro (UERJ) - onde se graduou - por meio da professora Sonia Barbosa dos Santos (docente do Instituto de Biologia). Com essa parceria, a autorização da direção da escola e das instâncias superiores, foi submetido e aprovado um projeto à Fundação Carlos Chagas Filho de Amparo à Pesquisa do Estado do Rio de Janeiro (FAPERJ), pleiteando apoio financeiro para a revitalização do laboratório de ciências da escola e para a 


\section{Blumenau, v.14, n.1, p.219-241, jan./abr. 2019 \\ DOI: http://dx.doi.org/10.7867/1809-0354.2019v14n1p219-241}

implantação do clube de ciências. A aprovação ${ }^{2}$ do projeto nesse edital foi um facilitador para o pontapé inicial do Clube de Ciências da referida escola.

O projeto funciona com encontros semanais, no contra turno das aulas regulares dos alunos, com um grupo pela manhã e outro à tarde. Podem participar do projeto qualquer aluno regularmente matriculado na escola, bastando apenas que seu responsável legal assine a autorização de participação no Clube e a autorização de uso de imagem e voz dos menores - momento em que este fica ciente de que todo e qualquer dado vinculado ao projeto somente poderá ser utilizado para fins educacionais.

As atividades desenvolvidas no Clube (práticas laboratoriais e de campo, leituras e discussões de texto, ciclo de palestras e visitas externas) partem do interesse prévio dos alunos. Inicialmente, os alunos respondem questionários e participam de debates para o diagnóstico dos tipos de atividades pertinentes à faixa etária e ao ano escolar dos educandos. No ano de 2012, percebemos o interesse na complementação de conteúdos que faziam parte da matriz curricular da escola, os quais não haviam sido assimilados por motivos distintos. No entanto, não ficamos restritos a esses temas, mas os utilizamos como temas geradores para alcançar muitos outros assuntos.

O ciclo de palestras (aberto a toda escola, ocorrendo no horário de almoço) foi planejado para acontecer semanalmente. Os palestrantes convidados são pesquisadores de diversas áreas do conhecimento, que comparecem à escola com o objetivo de dissertar sobre suas pesquisas, sua vida de pesquisador ou temas específicos relacionados ao seu trabalho, favorecendo a divulgação da ciência naquela unidade escolar. As palestras eram abertas a todos os alunos, professores e demais funcionários da escola; os alunos do Clube de Ciências faziam anotações para posteriores discussões sobre a palestra ou sobre o palestrante.

As visitas externas foram selecionadas para: a) aproximar ou aprofundar, quando possível, o tema tratado naquele bloco de atividades; b) aproximar os educandos da realidade científica e da própria ciência; c) motivar o aprendizado; e d) favorecer o conhecimento de espaços distantes da sua realidade. Alguns desses

2Projeto aprovado pelo processo E-26/110.103/2012 no edital de 2011 de "Apoio à melhoria do ensino em escolas públicas sediadas no Estado do Rio de Janeiro". 
 \\ Blumenau, v.14, n.1, p.219-241, jan./abr. 2019 \\ DOI: http://dx.doi.org/10.7867/1809-0354.2019v14n1p219-241}

espaços (museus, casas de ciências e laboratórios de pesquisas) eram inacessíveis para a maioria dos alunos, devido às condições financeiras e/ou desinteresse e desconhecimento da própria família. Antes das visitas, realizamos debates sobre as expectativas dos membros do Clube e, após as visitas, realizamos discussões e comparamos suas expectativas prévias e suas impressões reais. Algumas vezes os alunos confeccionaram textos e/ou desenhos.

Essa estratégia vem ao encontro do que Marandino (2001) fala sobre atividades em museus e que pode ser estendido aos outros espaços visitados. Segundo a autora, as atividades em museus são dinâmicas uma vez que "o aluno percebe diferentes formas de articulação entre os temas abordados" (MARANDINO, 2001, p.93), e contribuem na ampliação da "cultura científica dos cidadãos, promovendo diferentes formas de acesso a este saber, através de variados estímulos oferecidos ao público, diferentes daqueles da escola[...]" (MARANDINO, 2001, p.93). Além disso, os espaços visitados podem aproximar as discussões sobre como e por que aquele conhecimento está ali, quais os atores responsáveis pela sua produção etc.

Desse modo, o objetivo deste trabalho é apresentar as atividades externas realizadas pelo Clube e discutir como estas podem auxiliar na aquisição de conhecimento através da divulgação científica e da socialização da ciência entre esse grupo de alunos.

\section{DESENVOLVIMENTO}

A apresentação das atividades aqui descritas será feita a partir das anotações relacionadas aos planejamentos de cada atividade e às observações da professora responsável pelo projeto sobre as impressões dos alunos durante as visitas ou aquelas expostas em discussões posteriores. Logo, configura-se aqui um relato de experiência pedagógica. Esses dados compuseram o relatório anual de atividades do Clube e também ao que foi entregue à FAPERJ como relatório final de prestação de contas do projeto.

As visitas foram feitas a espaços de ensino não formal, como Museu Nacional, Museu da Vida, Observatório Nacional, Jardim Zoológico, Jardim Botânico 
Blumenau, v.14, n.1, p.219-241, jan./abr. 2019

DOI: http://dx.doi.org/10.7867/1809-0354.2019v14n1p219-241

e a Exposição "De Mendel a Venter: A Evolução da Ciência e o DNA", na UERJ; a laboratórios de pesquisa, como o Laboratório de Taxonomia de Poríferos e o Laboratório de Poliquetologia e Entomologia, e à Semana da Química no Instituto Federal de Ciência e Tecnologia do Rio de Janeiro.

Além dos alunos membros do Clube de Ciências, participaram destas visitas, como convidados, alunos da escola não-membros do Clube de Ciências (geralmente alunos dos anos finais do Ensino Fundamental ( $8^{\circ}$ e $9^{\circ}$ anos) indicados por seus professores), somando uma média de 38 alunos a cada visita. Nessas atividades, os alunos foram acompanhados por estagiários do projeto e por professores da escola, além das professoras responsáveis pelo Clube, sendo sempre um professor para cada grupo de dez alunos.

$\mathrm{Na}$ maioria das atividades externas, os alunos recebiam algum tipo de roteiro, que deveria ser preenchido ao longo das visitas, ou algum questionário, que deveriam preencher após as visitas. Esses registros tinham o objetivo de guiar algumas observações e auxiliá-los nos registros na visita, assim como para subsidiar discussões posteriores.

O Clube realizou essas atividades de três modos: transporte disponibilizado pela Prefeitura do Rio de Janeiro, transporte disponibilizado pelo IFRJ (para a Semana de Química no IFRJ) e transporte público.

\section{RESULTADOS}

No quadro 1, são apresentadas algumas atividades externas realizadas pelo Clube de Ciências entre os anos de 2012 e 2013.

Quadro 1: Atividades externas realizadas pelo Clube de Ciências.

\begin{tabular}{|c|c|c|}
\hline Visita & Objetivo & Contribuições da visita \\
\hline $\begin{array}{lr}\text { XXXII Semana de } \\
\text { Química: } & \text { IFRJ, } \\
\text { ciência e } & \text { cultura } \\
\text { ("Rio 20 } & \text { anos } \\
\text { depois") } & \end{array}$ & $\begin{array}{l}\text { Conhecer os trabalhos } \\
\text { científicos desenvolvidos } \\
\text { por estudantes do ensino } \\
\text { básico e da graduação e } \\
\text { estimular o interesse pela } \\
\text { pesquisa ao permitir o } \\
\text { contato com jovens } \\
\text { pesquisadores do Ensino }\end{array}$ & $\begin{array}{l}\text { A possibilidade de vivenciar trabalhos } \\
\text { desenvolvidos na área científica por estudantes } \\
\text { jovens que gostam da ciência possibilitou } \\
\text { compreender que há muitas áreas de trabalho } \\
\text { que não estão distantes da nossa realidade. } \\
\text { Também foi importante perceberem que muito do } \\
\text { que está presente em nosso cotidiano é fruto de } \\
\text { muita pesquisa e dedicação de cientistas. }\end{array}$ \\
\hline
\end{tabular}


Atos de Pesquisa em Educação - ISSN 1809-0354

Blumenau, v.14, n.1, p.219-241, jan./abr. 2019

DOI: http://dx.doi.org/10.7867/1809-0354.2019v14n1p219-241

\begin{tabular}{|c|c|c|}
\hline & $\begin{array}{l}\text { Médio, que apresentam } \\
\text { idades muito próximas às } \\
\text { deles. }\end{array}$ & $\begin{array}{l}\text { Os alunos também puderam conhecer o que foi a } \\
\text { Rio } 92 \text { e verificar, durante a visita, o que mudou e } \\
\text { o que permaneceu após } 20 \text { anos da Eco } 92 \\
\text { (Conferência das Nações Unidas sobre o Meio } \\
\text { Ambiente e o Desenvolvimento). }\end{array}$ \\
\hline Museu Nacional & $\begin{array}{l}\text { Conhecer } \\
\text { registradas em livros e } \\
\text { possibilitar ao aluno } \\
\text { vivenciar conhecimentos } \\
\text { que revelam a história de } \\
\text { civilizações antigas e atuais } \\
\text { em um espaço motivador }\end{array}$ & $\begin{array}{l}\text { Os alunos puderam conhecer culturas estudadas } \\
\text { em alguns livros didáticos, favorecendo o ensino- } \\
\text { aprendizagem em um espaço rico em } \\
\text { informações, possibilitando conhecer de perto a } \\
\text { história da sociedade, a origem e evolução da } \\
\text { vida e a chegada do homem às Américas. A visita } \\
\text { auxiliou na popularização e aprofundamento do } \\
\text { trabalho realizado pelo museu. }\end{array}$ \\
\hline Jardim Botânico & $\begin{array}{l}\text { Conhecer diferentes tipos } \\
\text { botânicos, principalmente } \\
\text { as espécies da flora } \\
\text { brasileira e ressaltar a sua } \\
\text { importância para } \\
\text { equilíbrio ambiental. }\end{array}$ & $\begin{array}{l}\text { Os alunos puderam conhecer plantas brasileiras e } \\
\text { como os pesquisadores trabalham para a } \\
\text { manutenção e preservação das espécies } \\
\text { utilizadas na produção de medicamentos. Tiveram } \\
\text { contato com plantas que comprometem a } \\
\text { manutenção da vida, porém são largamente } \\
\text { utilizadas pelo homem de modo indiscriminado. A } \\
\text { visita possibilitou o contato com um espaço aberto } \\
\text { e rico em conhecimentos, inclusive conhecimento } \\
\text { histórico, para um grupo escolar carente e que } \\
\text { não tem a oportunidade de acesso a uma área } \\
\text { como o Jardim Botânico devido à distância ou à } \\
\text { falta de interesse das famílias. }\end{array}$ \\
\hline $\begin{array}{l}\text { Jardim Zoológico } \\
\text { do Rio de Janeiro. }\end{array}$ & $\begin{array}{l}\text { Conhecer diferentes } \\
\text { animais, principalmente } \\
\text { espécies da fauna } \\
\text { brasileira, e compreender a } \\
\text { importância de preservação } \\
\text { das espécies ameaçadas. }\end{array}$ & $\begin{array}{l}\text { Os alunos puderam conhecer diversos animais e } \\
\text { tiveram a oportunidade de conhecer espécies } \\
\text { raras e ameaçadas de extinção. Durante a visita, } \\
\text { os alunos preencheram relatório a respeito dos } \\
\text { animais e puderam tirar dúvidas com os } \\
\text { monitores que acompanharam o grupo. Com essa } \\
\text { visita, o Clube possibilitou o desenvolvimento do } \\
\text { respeito à biodiversidade e ao meio ambiente, } \\
\text { além de dar oportunidade aos membros de } \\
\text { conhecerem o trabalho desenvolvido pelos } \\
\text { pesquisadores com os animais em cativeiro. }\end{array}$ \\
\hline $\begin{array}{lr}\text { Museu } & \text { de } \\
\text { Astronomia } & \text { e } \\
\text { Ciências Afins: } & \end{array}$ & $\begin{array}{l}\text { Estimular o interesse } \\
\text { científico nas áreas } \\
\text { visitadas (Astronomia, } \\
\text { Astrofísica, Geofísica e } \\
\text { Divisão do Serviço da } \\
\text { Hora); contribuir para a } \\
\text { compreensão destas áreas } \\
\text { do conhecimento e em } \\
\text { como estas contribuem } \\
\text { para a vida cotidiana. }\end{array}$ & $\begin{array}{l}\text { A atividade possibilitou aos alunos conhecerem } \\
\text { um pouco de Astronomia ainda antes da visita, a } \\
\text { partir de um vídeo sobre o Universo, com temas } \\
\text { que estavam sendo discutidos nos encontros do } \\
\text { Clube que culminaram no dia da visita. Os alunos } \\
\text { visitaram o espaço aberto sobre o Sistema Solar } \\
\text { e tiveram a oportunidade de participar de uma } \\
\text { conversa informal, no pátio da instituição, com um } \\
\text { astrofísico, que falou um pouco sobre o trabalho } \\
\text { que desenvolve e sobre a importância do estudo } \\
\text { da origem do Universo. Os alunos conheceram } \\
\text { um dos observatórios, descobriram como ocorre o } \\
\text { estudo do céu e como a hora do Brasil é } \\
\text { calculada e enviada para Brasília. Com mais essa } \\
\text { visita, nosso projeto contribuiu para o }\end{array}$ \\
\hline
\end{tabular}




\section{Atos de Pesquisa em Educação - ISSN 1809-0354 \\ Blumenau, v.14, n.1, p.219-241, jan./abr. 2019 \\ DOI: http://dx.doi.org/10.7867/1809-0354.2019v14n1p219-241}

\begin{tabular}{|c|c|c|}
\hline & & $\begin{array}{l}\text { desenvolvimento da Educação Científica } \\
\text { trabalhando em conjunto com o Museu de } \\
\text { Astronomia, assim como os demais espaços } \\
\text { visitados pelo Clube de ciências. }\end{array}$ \\
\hline $\begin{array}{l}\text { Museu da Vida } \\
\text { (Fundação } \\
\text { Oswaldo Cruz) } \\
\text { Exposições } \\
\text { visitadas: } \\
\text { "Semana do } \\
\text { cérebro" e visita } \\
\text { ao Parque da } \\
\text { Ciência. }\end{array}$ & $\begin{array}{l}\text { Estimular o interesse pelas } \\
\text { áreas científicas e vivenciar } \\
\text { na prática experimentos em } \\
\text { um espaço aberto e lúdico. }\end{array}$ & $\begin{array}{l}\text { Os alunos participaram da apresentação do Coral } \\
\text { da Fiocruz, que exibiu um repertório variado com } \\
\text { músicas que valorizavam o estudo da ciência. O } \\
\text { Museu ofereceu a exposição sobre a "Semana do } \\
\text { Cérebro", com a palestra da neurocientista Dra. } \\
\text { Ana Carolina Mendonça de Souza, cujo tema } \\
\text { abordou o funcionamento do cérebro com uma } \\
\text { linguagem fácil e acessível ao público presente. } \\
\text { Houve a visita ao Parque da Ciência, onde os } \\
\text { alunos participaram de experimentos e jogos } \\
\text { relacionados a temas como: energia, } \\
\text { comunicação, a importância da comunicação } \\
\text { sonora e escrita para a humanidade. Diante de } \\
\text { uma célula animal gigante, os educandos } \\
\text { puderam brincar e aprender ao mesmo tempo. A } \\
\text { visita ofereceu a oportunidade de conhecer uma } \\
\text { instituição de pesquisa muito importante na } \\
\text { história da pesquisa brasileira e na divulgação da } \\
\text { ciência e permitiu a exploração de temas } \\
\text { diversos. }\end{array}$ \\
\hline $\begin{array}{l}\text { Exposição na } \\
\text { UERJ: "De Mendel } \\
\text { a Verter: A } \\
\text { evolução da } \\
\text { Ciência e o DNA". }\end{array}$ & $\begin{array}{l}\text { Aproximar os educandos } \\
\text { de temas considerados } \\
\text { complexos, reforçar a } \\
\text { importância da pesquisa } \\
\text { sobre o DNA para a } \\
\text { humanidade, destacar a } \\
\text { importância das pesquisas } \\
\text { científicas e apresentar a } \\
\text { história e o esforço de } \\
\text { pesquisa de grandes } \\
\text { cientistas. }\end{array}$ & $\begin{array}{l}\text { Os alunos tiveram a oportunidade de aprender um } \\
\text { pouco sobre os cruzamentos genéticos e brincar } \\
\text { com os genótipos humanos. Os alunos se } \\
\text { encantaram com as explicações acerca dos } \\
\text { cromossomos sexuais e seus modelos, } \\
\text { participaram da extração do DNA da banana e } \\
\text { brincaram de montar as moléculas de DNA. A } \\
\text { exposição abordou o assunto de maneira lúdica, } \\
\text { sem deixar a precisão científica, e pôde mostrar } \\
\text { que é possível trabalhar assuntos complexos de } \\
\text { modo acessível ao público heterogêneo presente } \\
\text { à exposição. A abordagem do tema contribuiu } \\
\text { para o projeto com o enfoque de temas } \\
\text { complexos de modo lúdico e acessível à } \\
\text { mediação dos conhecimentos. }\end{array}$ \\
\hline $\begin{array}{lr}\text { Visita } & \text { ao } \\
\text { Laboratório } & \text { de } \\
\text { Taxonomia } & \text { de } \\
\text { Poríferos } & \text { (Taxpor) } \\
\text { UFRJ } & \text { (Museu } \\
\text { Nacional) } & \end{array}$ & $\begin{array}{l}\text { Conhecer um laboratório de } \\
\text { pesquisa e seus } \\
\text { pesquisadores, } \\
\text { compreender o papel } \\
\text { destes no estudo científico } \\
\text { e aproximar os estudantes } \\
\text { da pesquisa científica. }\end{array}$ & $\begin{array}{l}\text { Os alunos puderam vivenciar na prática a atuação } \\
\text { do pesquisador em um laboratório. Conheceram } \\
\text { espécies de poríferos só vistos em livros de } \\
\text { biologia. Conheceram a coleção científica do } \\
\text { laboratório e sua importância. Conversaram com } \\
\text { os pesquisadores e diferenciaram o laboratório da } \\
\text { escola ao de uma grande instituição de pesquisa. } \\
\text { A visita possibilitou aos alunos o contato com o } \\
\text { trabalho científico, na prática do cotidiano de um } \\
\text { laboratório de pesquisa, além de permitir o } \\
\text { contato de cientistas com um grupo distinto aos } \\
\text { quais estão habituados a apresentar seu trabalho. }\end{array}$ \\
\hline $\begin{array}{l}\text { Visita } \\
\text { Laboratório }\end{array}$ & $\begin{array}{l}\text { Conhecer uma variedade } \\
\text { de animais só vistos em }\end{array}$ & $\begin{array}{l}\text { Os alunos conheceram no labc } \\
\text { variedade de invertebrados e apr }\end{array}$ \\
\hline
\end{tabular}


Atos de Pesquisa em Educação - ISSN 1809-0354

Blumenau, v.14, n.1, p.219-241, jan./abr. 2019

DOI: http://dx.doi.org/10.7867/1809-0354.2019v14n1p219-241

\begin{tabular}{|lr|l|l|}
\hline $\begin{array}{l}\text { Poliquetologia } \\
\text { Entomologia da } \\
\text { UERJ. }\end{array}$ & $\begin{array}{l}\text { livros didáticos e vivenciar } \\
\text { um pouco do trabalho } \\
\text { desenvolvido } \\
\text { cientistas na vida diária em } \\
\text { um laboratório. }\end{array}$ & $\begin{array}{l}\text { pouco sobre o comportamento desses animais na } \\
\text { natureza, fizeram perguntas e se encantaram com } \\
\text { as caixas entomológicas. A Profa. Dra. Alexandra } \\
\text { Rizzo explicou um pouco sobre a anatomia dos } \\
\text { anelídeos, hirudíneos e poliquetas. Os alunos } \\
\text { puderam manusear os espécimes e fazer } \\
\text { observações ao estereomicroscópio com o auxílio } \\
\text { dos alunos da graduação em biologia da } \\
\text { instituição. A visita favoreceu o projeto com } \\
\text { conteúdos que se somaram ao trabalho } \\
\text { desenvolvido pelo Clube na montagem de suas } \\
\text { caixas entomológicas, e aproximou esses alunos } \\
\text { de uma instituição de ensino e pesquisa, de seus } \\
\text { pesquisadores e de seus laboratórios, } \\
\text { favorecendo a troca de experiências entre estes e } \\
\text { a introdução à cultura científica. }\end{array}$ \\
\hline
\end{tabular}

Fonte: Dados de pesquisa compilados pelos autores.

\section{DISCUSSÃO}

Segundo Watanabe e Kawamura (2011), quando aproximamos a ciência dos alunos, estamos promovendo a compreensão do papel da ciência na sociedade, da ciência como uma criação humana, facilitando a inserção da cultura científica na realidade desses alunos e realizando uma iniciação a outras formas de ver o mundo.

Sobre isso, Jenkins (1999) afirma que é necessário que os cidadãos tenham formação científica de modo que sejam "capazes de contribuir na tomada de decisões sobre assuntos sociais que tenham dimensões científicas" (p. 703, tradução nossa). Isto porque a educação científica permite que a população adquira informações do funcionamento da ciência e das pesquisas científicas, o que poderá habilitá-la na tomada de decisões diante das discussões socioambientais, por exemplo. Como uma aluna do ensino básico de Portugal (de um grau equivalente ao ensino médio brasileiro) falou em entrevista, à pesquisa de Reis e Galvão (2006, p. 224), a "ciência não é uma exclusividade dos cientistas", a ciência afeta a sociedade. Logo, é preciso que as pessoas tenham informações para poder opinar sobre assuntos referentes a ela podendo, inclusive, junto ao Estado, avaliar as pesquisas, como um modo de controle social.

É direito do cidadão ter acesso à ciência. E é devido ao trabalho de muitas pessoas que esse direito vem sendo acessado pela população (CARIBÉ; MUELLER, 2010). Estes foram parte do objetivo das visitas promovidas pelo Clube de Ciênciasmacr: aproximar a ciência de modo a capacitar os alunos, em algum nível, a 
 \\ Blumenau, v.14, n.1, p.219-241, jan./abr. 2019 \\ DOI: http://dx.doi.org/10.7867/1809-0354.2019v14n1p219-241}

pensar, discutir e posicionar-se de forma coerente e crítica diante de variadas informações.

O que pretendemos com essas atividades é reduzir o que Freire (1996) chama de poder invisível da domesticação alienante que desconsidera a formação integral do ser humano, reduzindo-a a um mero treinamento e fortalecendo o autoritarismo daqueles que, por possuírem o conhecimento, falam "de cima para baixo" (FREIRE, 1996, p.113) . Daí a importância do acesso à ciência como modo de auxiliar na formação dos indivíduos; formação essa que viabilizará o pensamento crítico levando à discussão crítica, ao invés de silenciá-los e formá-los para simplesmente acatarem toda informação que chega até eles. Por isso, consideramos que a divulgação científica tem um papel importante nessa formação.

Discutiremos a seguir os efeitos que a divulgação científica, dos espaços visitados, possa ter causado em nosso grupo de alunos. Embora os zoológicos e os Jardins Botânicos não tenham como objetivos principais a divulgação científica, podem ser considerados fontes eficientes de popularização da ciência (ALBAGLI, 1996), e falaremos sobre eles considerando esse aspecto.

Os museus visitados e o Jardim Zoológico disponibilizaram visitas guiadas, algumas com manipulação de algum tipo de instrumento ou a participação direta na explicação e/ou experimento. Segundo Massarani e Moreira (2010), o incentivo à interatividade nos espaços não formais de ensino vem aumentando nos últimos anos. Essa interatividade foi experimentada no Museu da Vida, em alguns setores do Museu de Astronomia e Ciências Afins e na exposição apresentada na UERJ. Segundo Valente; Cazelli; Alves (2005), essa é uma solução que permite o compartilhamento e a participação do público visitante, aumentando a motivação, a interatividade e o interesse, além de facilitar a compreensão e a aquisição de conhecimento. Esse tipo de método, chamado de hands-on, também tem como objetivo incentivar o envolvimento direto, a iniciativa individual e a curiosidade do visitante (ALBAGLI, 1996). Os alunos realmente sentiram-se desta forma: aprenderam de modo divertido, interessante e motivador. Esse sentimento também foi experimentado pelos professores e estagiários que acompanharam o grupo.

O Museu Nacional, o Museu de Astronomia e Ciências Afins, o Museu da Vida e até mesmo o Jardim Botânico, em certo ponto, apresentaram temas diversos, 
 \\ Blumenau, v.14, n.1, p.219-241, jan./abr. 2019 \\ DOI: http://dx.doi.org/10.7867/1809-0354.2019v14n1p219-241}

explorando questões científicas, considerando aspectos históricos envolvidos na produção daqueles conhecimentos, entre outros. Quanto a isso, Peixoto e GuedesBruni (2010) afirmam que o Jardim Botânico do Rio de Janeiro "guarda em si a memória da transformação do país ao preservar plantas introduzidas na época de sua criação[...]" (PEIXOTO; GUEDES-BRUNI, 2010, p. 34). Assim, identificamos que as exposições trouxeram à tona questões que extrapolam aqueles espaços, que envolvem temas que, muitas das vezes, não concebíamos como concernentes àqueles locais, a exemplo dos aspectos políticos e culturais relacionados ao Jardim Botânico e ao Museu Nacional. Segundo Valente; Cazelli; Alves (2005) e Valente (2005), isso facilita a compreensão de que a ciência é um processo humano desenvolvido de modo coletivo, que envolve questões sociais e culturais (e acrescentamos aqui), implicam interesses e entraves políticos, econômicos e pessoais. Isso promove o entendimento da não neutralidade da ciência, desta como uma produção humana e as relações sociais que, de uma forma ou de outra, perpassam a produção científica. Contudo, nem sempre esses espaços estão preparados para apresentar esses aspectos da ciência (MARANDINO, 2005). Esse é um dos motivos pelo qual que essas atividades se fazem importantes para grupos marginalizados, uma vez que precisam compreender o porquê pode haver desinteresse em disponibilizar este acesso a todos os grupos sociais e como podemos mudar esse panorama.

Para Valente (2005), é extremamente importante concebermos os museus não apenas como local depositário de coleções, com a respectiva preservação, mas como locais de comunicação de cultura, que amplia o conhecimento e a possibilidade de desfrute deste.

Um ponto interessante destacado por físicos da USP entrevistados por Watanabe e Kawamura (2011), e que foi percebido durante as nossas visitas nesses espaço, é que deve ser apresentada aos visitantes de museus a parceria, muitas das vezes necessária, entre os laboratórios de pesquisas/museus e arqueólogos para atestar a autenticidade de obras de arte e determinar a data de artefatos arqueológicos, por exemplo. Segundo eles, essas informações, tratadas durante as visitas aos museus e às casas de ciência com seu público, podem levar a uma visão integrada da ciência e o entendimento de que muito do que vemos e desfrutamos é 


\section{Atos de Pesquisa em Educação - ISSN 1809-0354}

\section{Blumenau, v.14, n.1, p.219-241, jan./abr. 2019}

DOI: http://dx.doi.org/10.7867/1809-0354.2019v14n1p219-241

consequência de trabalho científico coletivo. Isso se torna importante inclusive porque é uma forma de aproximar as ciências naturais e sociais. Sobre isso, Valente (2005) afirmou que essa abordagem realizada pelos museus é oportuna, já que é evidente esta cisão e a dificuldade de entendimento de questões éticas, culturais e políticas que envolvem a produção científica. Segundo a autora, esses assuntos aumentam a capacidade do pensamento crítico dos visitantes.

Albagli (1996) afirmou, e isto ainda hoje se confirma, que os centros de ciência e museus representam apenas parte dos esforços para tornar a ciência acessível. Há iniciativas que vêm crescendo ao longo dos anos, trabalhando para esta divulgação. Exemplos disso são as exposições e a abertura das instituições de ensino e pesquisa para o recebimento de grupos interessados em conhecer mais a produção científica. Algumas dessas atividades foram experimentadas pelo grupo do Clube de Ciências e é sobre estas que falamos a seguir.

As exposições na UERJ, as apresentações dos projetos de pesquisa discentes na Semana de Química do IFRJ e as visitas aos laboratórios de pesquisa se aproximam por mostrar não só parte da história de um dado conhecimento, mas também o seu desenvolvimento prático. Os alunos visitantes conheceram o passo a passo de alguns experimentos e pesquisas, acessaram ambientes reais onde se faz ciência e conversaram de perto com cientistas. Nessas atividades, foi possível aos alunos se deparar mais profundamente com outra cultura, que até então não tinham conhecido, além da possibilidade do contato com cientistas muito jovens do IFRJ, o que pode ter motivado nossos alunos.

Segundo Benedict (2005), a cultura aprendida por um indivíduo é consequência do que ele herda de seu entorno, de sua comunidade. Sua fala, seus hábitos, suas crenças, suas possibilidades e suas impossibilidades são fruto do seu meio. Logo, entendemos que estes alunos estavam imersos num mar de impossibilidades de conhecer, conviver e entender a ciência e isso impossibilitava a compreensão da ciência que os cerca, e restringia sua visão do mundo. A partir do momento em que se abriram portas, que lhes foi apresentada uma nova cultura, nesse caso, a cultura científica (ou a compreensão da ciência como cultura) -, esse novo conhecimento pode ser elaborado e compreendido, e isto pode ser incorporado à sua realidade. Assim, sua fala, seus hábitos suas crenças e possibilidades tiveram 


\title{
Atos de Pesquisa em Educação - ISSN 1809-0354 \\ Blumenau, v.14, n.1, p.219-241, jan./abr. 2019 \\ DOI: http://dx.doi.org/10.7867/1809-0354.2019v14n1p219-241
}

a oportunidade de mudar, ampliando sua visão do mundo e concedendo-lhes componentes para a construção de novas opiniões sobre temas variados.

A incorporação de uma nova cultura não seria possível apenas com as atividades do ensino formal ou com as atividades realizadas no Clube de Ciências. Inclusive, Fensham (1999) afirmou que grande parte dos conhecimentos científicos atuais e mais relevantes, adquiridos pela população adulta, não resultaram de atividades realizadas no ensino formal, mas sim da influência das diversas mídias e de espaços não formais de ensino. Albagli (1996) discutiu com alguns autores e também afirmou que somente a escola não é capaz de disponibilizar e nem promover as informações científicas relevantes para os indivíduos ao longo de toda sua vida; sendo, consequentemente, necessária a parceria com espaços mais flexíveis que o ensino formal para a abordagem de novos e complexos temas.

Considerando esses aspectos, Watanabe e Kawamura (2011) afirmaram que:

\begin{abstract}
Apesar de não haver, ainda, no campo da educação, uma metodologia científica capaz de trazer à tona aspectos culturais da ciência, do ponto de vista do culturalismo, que possam vir a ser contemplados nas práticas pedagógicas, acredita-se que a aproximação dos fazeres da cultura científica possa representar um espaço em potencial para isso. Assim, por exemplo, visitas ou atividades em espaços como laboratórios científicos podem ser importantes meios de interlocução entre a escola básica e a cultura científica. Essa crença vem do fato de que os indivíduos são importantes representantes da cultura a que pertencem e a interação com estudantes, podem trazer relevantes mudanças na forma com que ambos cientista e aluno - reconhecem a cultura do outro.

Pensar nesse sentido é uma forma de se investigar a possibilidade de produção de visitas em espaços não-formais, capaz de apresentar aspectos culturais que a escola não dá conta de proporcionar, seja pela limitação do seu espaço físico, seja pela complexidade da dimensão cultural do objeto a ser abordado. Assim, tais reflexões pretendem exemplificar algumas questões relacionadas a esse campo, no caso específico de visitas monitoradas, na medida em que o processo de aculturação ${ }^{3}$ subentende a mediação entre diferentes perspectivas como possíveis espaços de diálogo entre grupos culturais distintos (WATANABE; KAWAMURA, 2011, p. 6).
\end{abstract}

Ainda nesta pesquisa sobre aculturação científica, Watanabe e Kawamura (2011) afirmam ter identificado, na fala dos pesquisadores entrevistados que têm aberto seus laboratórios para visita de alunos, uma preocupação social que envolve algum tipo de retorno de suas pesquisas para a sociedade. Acreditamos que também foi isso que mobilizou os pesquisadores parceiros do Clube de Ciências não só para as palestras, mas também para abertura de seus laboratórios para visitação

\footnotetext{
${ }^{3}$ Segundo Watanabe e Kawamura (2011) a aculturação planejada se refere a uma significação dos sistemas de valores de indivíduos que recebem elementos de uma nova cultura.
} 
 \\ Blumenau, v.14, n.1, p.219-241, jan./abr. 2019 \\ DOI: http://dx.doi.org/10.7867/1809-0354.2019v14n1p219-241}

e, de certa forma, foi o que também incentivou a apresentação das pesquisas desenvolvidas pelos alunos do IFRJ.

Parece-nos que, assim como em vários momentos da história da divulgação científica, atualmente vem crescendo a valorização da aproximação do público com a ciência, inclusive no sentido inverso: as pesquisas têm ido até as escolas através de projetos de extensão. Exemplo disso é o projeto desenvolvido pela Fundação Centro Universitário da Zona Oeste (UEZO), que leva conhecimentos antes restritos aos laboratórios da universidade às escolas públicas e suas comunidades, com objetivo de colaborar para a divulgação de conhecimentos que podem, inclusive, provocar na população uma postura que the assegure qualidade de vida (KIFFER, 2014).

Sobre a nossa visita aos laboratórios de pesquisa, identificamos que ocorreu uma rica troca entre os alunos e os pesquisadores. Embora houvesse duas culturas distintas, o diálogo se desenrolou de modo fácil, permitindo a divulgação das pesquisas desenvolvidas e conhecimentos adquiridos pelos cientistas, incentivando as falas e a apresentação dos pontos de vista dos alunos, e marcando, de maneira positiva, os dois grupos, diferentemente do que foi identificado por Watanabe e Kawamura (2011) na entrevista com os físicos da USP. Esses cientistas receberam em seu laboratório alunos do ensino básico em algumas ocasiões. Ainda assim, as autoras perceberam que houve uma dificuldade no diálogo entre as duas culturas: os pesquisadores tiveram dificuldades de compreender que esses grupos precisam receber informações menos específicas e que a visita deve ser um momento de aquisição cultural, de modo que possa acrescentar aos alunos um pouco da cultura científica. No entanto, é necessário que essas informações façam sentido para o público ouvinte/visitante e que Ihes permitam alguma leitura. As pesquisadoras afirmam que isto é compreensível, devido às diferentes demandas advindas da cultura escolar. Daí a importância da mediação entre alunos do ensino básico e os cientistas, de modo que consigam manter algum tipo de comunicação, para que seja possível contemplar as necessidades e interesses de ambos os grupos. 


\section{CONSIDERAÇÕES FINAIS ${ }^{4}$}

Os espaços visitados alcançaram nossas expectativas de aumentar o entendimento sobre a finalidade e importância da ciência na sociedade por meio de ações e experiências educativas, despertando o interesse dos alunos e criando perspectivas de aproximações futuras, tal como Jacobucci (2008) apresentou.

É evidente que o público atendido pelo Clube de Ciências, beneficiado com essa experiência, é muito pequeno quando comparado à população da região onde a unidade de ensino se localiza - não chega a $4 \%$ do total de alunos da nossa escola. Mas esse trabalho lembra o ofício de formiguinhas, lento e coletivo, do qual somente se identificarão os resultados em longo prazo. Assim, acreditamos que, mesmo contemplando poucos indivíduos, aqueles que participaram dessas atividades, conheceram e foram tocados de alguma forma pela ciência, poderão ser multiplicadores desses conhecimentos, dessas visões e de sonhos. Mas isto poderia e deveria ser diferente: o alcance deste tipo de ação precisa ser maior.

Acreditamos que o objetivo de realizar a divulgação da ciência poderia ser atingido por várias escolas, disponibilizando o acesso e informações de qualidade, facilitando a inserção da cultura científica na realidade dos alunos a partir do momento em que se democratiza a ciência, aproximando-a destes indivíduos, de modo a permitir a compreensão do seu papel na sociedade. Isso estimulará o seu desenvolvimento social, concederá a eles argumentos para questionar informações apresentadas pela mídia, pelo ensino formal, por colegas ou por quem quer que seja. Concordamos com Valente; Cazelli; Alves (2005, p. 201) quando afirmaram que "um público mais culto cientificamente estará em melhor posição para discutir, acompanhar e reivindicar políticas públicas referentes às questões atuais e controversas da ciência" e para se posicionarem livremente sobre a ciência com um mínimo de conhecimento. Logo, a socialização da ciência e a apropriação desta pela sociedade são instrumentos de cidadania e uma forma de inclusão social.

Dessa forma, e considerando a formação cidadã recorrente nos textos da Constituição Federal (BRASIL, 1988), da Lei de Diretrizes e Bases da Educação

4 A presente pesquisa foi desenvolvida com recursos provenientes dos processos E-26/110.103/2012 e E-26/111.927/2013 - APQ1 da Fundação Carlos Chagas Filho de Amparo à Pesquisa do Estado do Rio de Janeiro (FAPERJ). 


\section{Atos de Pesquisa em Educação - ISSN 1809-0354}

\section{Blumenau, v.14, n.1, p.219-241, jan./abr. 2019}

DOI: http://dx.doi.org/10.7867/1809-0354.2019v14n1p219-241

(BRASIL, 1996), dos Parâmetros Curriculares Nacionais (PCN) (BRASIL, 1998a) e das Diretrizes Curriculares Nacionais para o Ensino Médio (BRASIL, 1998b), a divulgação científica deveria fazer parte do Plano Nacional de Educação, das Diretrizes Estaduais e Municipais de Educação e dos Projetos Políticos Pedagógicos de cada unidade escolar. Da mesma forma, a divulgação científica deveria ser tratada durante os cursos de graduação e de formação continuada de professores como um dos pontos principais para a construção da cidadania.

Essas ações podem ser estratégias de aproximação entre a escola e a ciência: afinal, não basta lutar para a descentralização ${ }^{5}$ dos museus e centros de ciências se a escola não se aproximar deles. Sobre esse assunto, desejamos destacar uma fala de Sibele Cazelli (informação verbal) ${ }^{6}$ no I Fórum Sobre Inclusão em Centros e Museus de Ciência e Tecnologia, quando citou que a maioria das escolas que visitam o Museu de Astronomia e Ciências Afins - MAST (no bairro de São Cristóvão, na cidade do Rio de Janeiro) têm localização distante, são oriundas, principalmente, de outras cidades do Estado. O mesmo acontece com outros centros de ciências e Museus (KÖPTCKE; CAZELLI; LIMA, 2008).

Ainda que haja um esforço das casas de ciências e de museus, tais como projetos de museus itinerantes e a disponibilização de transportes, é preciso que o Estado incentive escolas e docentes e também forneça subsídios para essa aproximação.

Mas, enquanto isto não acontece de modo efetivo, nosso projeto segue tentando realizar esta mediação visando ao objetivo de divulgar a ciência nas formas que forem possíveis, favorecendo uma formação científica aos alunos envolvidos.

\section{PATRÍCIA DO SOCORRO DE CAMPOS DA SILVA}

Mestre em Ensino de Ciências pelo Instituto Federal do Rio de Janeiro (IFRJ). Especialista em Ensino de Ciências pelo IFRJ. Professora da Rede Estadual do Rio de Janeiro e da Rede Municipal de Educação da Cidade do Rio de Janeiro e da Secretaria de Estado de Educação do Estado do Rio de Janeiro.

\footnotetext{
${ }^{5} \mathrm{Na}$ cidade do Rio de Janeiro a região do Centro, Tijuca e zona sul (Copacabana, Botafogo, etc.) abriga $25 \%$ da população residente na cidade, mas dispõe de $86 \%$ dos Museus (KÖPTCKE; CAZELLI; LIMA, 2008).

6Informação fornecida durante a mesa redonda "Museu e Inclusão Sociocultural" por Sibele Cazelli. Sibele é pesquisadora da Coordenação de Educação em Ciências /Museu de Astronomia e Ciências Afins - MAST/MCTI.
} 


\title{
Atos de Pesquisa em Educação - ISSN 1809-0354
}

\author{
Blumenau, v.14, n.1, p.219-241, jan./abr. 2019
}

DOI: http://dx.doi.org/10.7867/1809-0354.2019v14n1p219-241

\section{SONIA BARBOSA DOS SANTOS}

Doutora em Zoologia pela Universidade de São Paulo (USP). Mestre em Zoologia pela Universidade Federal do Rio de Janeiro (UFRJ-Museu Nacional). Licenciada e Bacharel em Ciências Físicas e Biológicas pelo Instituto de Biologia da UERJ. Especialista em Sistemática Zoológica pela UFJF. Docente do Instituto de Biologia da Universidade Estadual do Rio de Janeiro (UERJ). Docente do Programa de PósGraduação em Ecologia e Evolução da UERJ.

\section{GISELLE FONSECA RÔÇAS}

Doutora em Ecologia pela Universidade Federal do Rio de Janeiro (UFRJ). Mestre em Ecologia pela UFRJ. Bacharel em Ciências Biológicas, modalidade Ecologia pela UFRJ. Docente do Programa de Pós-Graduação Stricto Sensu em Ensino de Ciências do Instituto Federal do Rio de Janeiro (IFRJ).

\section{REFERÊNCIAS}

ALBAGLI, S. Divulgação científica: informação científica para a cidadania? Ciência e Informação. Brasília, v. 25, n. 3, p. 396-404, 1996.

ALMEIDA, A. M. O contexto do visitante na experiência museal: semelhanças e museus de ciência e de arte. História, Ciências, Saúde - Manguinhos, Rio de Janeiro, v. 12 (suplemento), p. 31-53, 2005.

BARATA, G. Papel social do cientista inclui divulgar seu trabalho. Ciência e Cultura, Campinas, v.60, n.1, p. 12-14, 2008.

BENEDICT, R. Patterns of Culture. Nova York: Mariner Books, 2005.

BRASIL. Conselho Nacional de Educação. Parecer CNE/CEB n. ${ }^{\circ}$ 15/98, 01 de junho de 1998. 1998a. Disponível em:

<http://www.crmariocovas.sp.gov.br/pdf/diretrizes_p0401-0466_c.pdf>. Acesso em: 07 jan.2018.

BRASIL. MEC/ Secretaria de Educação Fundamental. Parâmetros Curriculares Nacionais: terceiro e quarto ciclos do ensino fundamental: introdução aos parâmetros curriculares nacionais. Brasília: 1998b. 174p

BRASIL. Senado. Lei n. ${ }^{\circ}$ 9394, de 20 de dezembro de 1996. 1996. Disponível em:<https://www2.senado.leg.br/bdsf/bitstream/handle/id/70320/65.pdf>. Acesso em: 07 jan. 2018.

BRASIL. Constituição Federal do Brasil. Brasília: Senado, 1988.

CALVO HERNANDO, M. Arte y ciencia de divulgar el conocimiento, Quito (Ecuador): Ciespal, 2006.

DUARTE, J. Da divulgação científica à comunicação. Revista Acadêmica do Grupo Comunicacional de São Bernardo. São Bernardo. Ano 1, n. 2, 2004. Disponível em: 


\section{Atos de Pesquisa em Educação - ISSN 1809-0354 \\ Blumenau, v.14, n.1, p.219-241, jan./abr. 2019 \\ DOI: http://dx.doi.org/10.7867/1809-0354.2019v14n1p219-241}

<http://www2.metodista.br/unesco/GCSB/reproducao_divulgacao.pdf>. Acesso em: 07 mar. 2016.

ESTEVES, B.; MASSARANI, L.; MOREIRA I. C. Ciência para Todos - análise de um suplemento de divulgação científica (1948-1953). In: II Congresso Luso-Brasileiro de História da Ciência e da Tecnologia/ IX Seminário Nacional de História da Ciência e da Tecnologia, 2003, Rio de Janeiro. Caderno de Resumos. Rio de Janeiro:

Sociedade Brasileira de História da Ciência/Museu de Astronomia e Ciências Afins, p. 28-29, 2003.

FENSHAM, P. School science and public understanding of science. International Journal of Science Education, Londres, v. 21, n. 7, p. 755-63, 1999.

FREIRE, P. Pedagogia da autonomia: saberes necessários à prática educativa. São Paulo: Paz e Terra, 1996.

GIL-PÉREZ, D.; et al. Por uma imagem não deformada do trabalho científico. Ciência e Educação, Bauru, v.7, n.2, p.125-153, 2001.

IVANISSEVICH, A. A missão de divulgar ciência no Brasil. Ciência e Cultura, Campinas, v. 61, n.1, p. $4-5,2009$.

IPP- INSTITUTO PEREIRA PASSOS. Armazém dos dados/bairros cariocas. Rio de Janeiro: 2004. Disponível em: <www.portalgeo.rio.rj.gov.br>. Acesso em 24 mai. 2015.

ISP- INSTITUTO DE SEGURANÇA PÚBLICA. Rio de Janeiro: 2015. Estatísticas. Dados oficiais. Disponível em: <www.isp.rj.gov.br/dadosoficiais.asp>. Acesso em 21 jan. 2015.

JACOBUCCI, D.F.C. Contribuições dos espaços não-formais de educação para a formação da cultura científica. Em Extensão, Uberlândia, v. 7, p. 55-66, 2008.

JENKINS, E. School science, citizenship and the public understanding of science. International Journal of science Education, Londres, v. 21, n. 7, p. 703 - 710, 1999.

KIFFER, D. Para despertar futuras vocações: Pesquisadores da UEZO promovem difusão e popularização da Ciência nas escolas públicas da Zona Oeste. Rio Pesquisa (FAPERJ). Ano VII, n. 28. p. 27 - 29, 2014.

KRASILCHIK, M. O professor e o currículo de ciências. São Paulo: EPU; EDUSP, 1987.

KÖPTCKE, L. S.; CAZELLI, S.; LIMA, J. M. de. Museus e seus visitantes: relatório de pesquisa perfil-opinião 2005. Brasília: Gráfica e Editora Brasil, 2008.

MARANDINO, M. A pesquisa educacional e a produção de saberes nos museus de ciência. História, Ciências, Saúde-Manguinhos, Rio de Janeiro, v. 12 (suplemento), p. 161-81, 2005.

MARANDINO, M. Interfaces na Relação Museu-Escola. Caderno Catarinense de Ensino de Física, Florianópolis, v.18, n.1, p.85-100, 2001. 


\section{Atos de Pesquisa em Educação - ISSN 1809-0354 \\ Blumenau, v.14, n.1, p.219-241, jan./abr. 2019 \\ DOI: http://dx.doi.org/10.7867/1809-0354.2019v14n1p219-241}

MASSARANI, L.; MAGALHÃES, I.; MOREIRA, I. C. Quando a ciência vira notícia: um mapeamento da genética nos jornais diários. Ciência e Ambiente, Santa Maria,v. 26, n.1, p.141-148, 2003.

MASSARANI, L.; MOREIRA, I. C. A divulgação científica no Rio de Janeiro: um passeio histórico e o contexto atual (Dossiê temático). Revista Rio de Janeiro, Rio de Janeiro, n. 11, p. $38-69,2003$.

MASSARANI, L.; MOREIRA, I. C. Miguel Ozório de Almeida e a vulgarização do saber. História, Ciências, Saúde - Manguinhos, Rio de Janeiro, v. 11, n. 2, p. 50113, 2004.

MUELLER, S. P. M.; CARIBÉ, R. C. V. Comunicação científica para o público leigo: breve histórico. Informação e Informação, Londrina, v. 15, n. esp, p. 13 - 30, 2010.

PEIXOTO, A. L.; GUEDES-BRUNI, R. R. No Rio de Janeiro, um Jardim Botânico bicentenário. Ciência e Cultura, Campinas, v. 62, n.1, p. 32-35, 2010.

REIS, P.; GALVÃO, C. O diagnóstico de concepções sobre os cientistas através da análise e discussão de histórias de ficção científica redigidas pelos alunos. Revista Electrónica de Enseñanza de las Ciencias, Ourense, v.5, n.2, p.213-234, 2006.

SCHWARZTMAN, S. Um espaço para a ciência: a formação da comunidade científica no Brasil. Brasília, DF: MCT, Centro de Estudos Estratégicos, 2001.

Disponível em <http://www.schwartzman.org.br/simon/spacept/espaco.htm>. Acesso em 05 jan. 2018.

SILVA, H. C. O que é divulgação científica? Ciência e Ensino, São Paulo, v. 1, n. 1, p. 53-59 2006.

TOMÁS, J. P. De los libros de secretos a los manuales de la salud: cuatro siglos de popularización de la ciencia. Quark, Barcelona, n. 37 e 38, set.2005/abr.2006.

Disponível em: <http://quark.prbb.org/37-38/037030.pdf>. Acesso em 05 jan. 2018.

VALENTE, M. E. A. O museu de ciência: espaço da história da ciência. Ciência e Educação, Bauru, v. 11, n. 1, p. 53-62, 2005.

VALENTE, M. E. A.; CAZELLI, S.; ALVES, F. M. Ciência e educação: novos desafios. História, Ciências, Saúde - Manguinhos, Rio de Janeiro, v. 12 (suplemento), p. 183-203, 2005.

WATANABE, G.; KAWAMURA, M. R. D. A cultura da ciência e a educação científica: a fala dos cientistas de um laboratório e as possibilidades de uma aculturação planejada. In: VIII Encontro Nacional de Pesquisa em Educação em Ciências. Campinas, São Paulo, 2011. Anais eletrônicos. Disponível em: <http://www.nutes.ufrj.br/abrapec/viiienpec/resumos/R0030-2.pdf>. Acesso em 20 dez. 2014. 